\title{
Humorous nonsense and multimodality in British and American children's poetry
}

\author{
Elżbieta Chrzanowska-Kluczewska \\ Jagiellonian University in Krakow \\ elzbieta.chrzanowska-kluczewska@uj.edu.pl
}

\begin{abstract}
Nonsense and humour are two cognitive and linguistic phenomena that frequently overlap. The focus of this article falls on chosen instances of humorous nonsense poetry, targeted at English-speaking children, which contains verbal and visual modes of expression.

Formal sources of nonsense-creation in natural language can be several, among others semantic anomaly, syntactic ill-formedness and structural ambiguity, phonetic and graphological experimentation.

The interplay of nonsense with the visuality of the text in children's poetry assumes three distinct forms: 1) visual poems, 2) multimodal texts, where illustrations, often nonsensical and funny in themselves, support the verbal text, and 3) texts based on the phonetic play. Examples will be drawn from the classics of the Anglophone children's poetry: Mother Goose, the Victorian classics L. Carroll and E. Lear, $20^{\text {th }}$ century British and American poets - L. Hughes, e. e. cummings, T. Hughes, J. Agard, as well as the Polish-British pair W. Graniczewski and R. Shindler.

In all the poems to be analysed multimodality has an important role to play in the creation and strengthening of the effect of humorous bisociation/incongruity. A tight intertwining of the phonetic, semantic, and visual layers in such texts becomes an additional challenge for their translators.

The theoretical keystone for our considerations remains Henri Bergson's study Laughter (1900/2008), which deftly combines the superiority, the incongruity, and the release theory of modern humour studies. Bergson rightly links the sources and effects of the nonsensical and the comic to the notion of game/play and to the idea of dream-like illusion they create.
\end{abstract}

Keywords: children's poetry, nonsense, humour, multimodality, visual modality. 


\section{Nonsense triggers in natural language}

Nonsense and humour are two cognitive and linguistic phenomena that frequently accompany each other. Although over the centuries nonsense literature has been created for various groups of readers - adult and young receivers alike - the focus of this article falls on selected instances of multimodal humorous nonsense poetry targeted at English-speaking children. Our interest lies in a double-mode character of this genre of literature, which is either visual on its own or accompanied by illustrations. It is this perceptual multimodality that makes nonsense literature for children specific, distinguishing it from absurdist literature directed at the mature readership, which is typically monomodal, i.e. verbal, with the exception of the dramatic genre called the theatre of the absurd (which relies on the mixed verbal-visual-acoustic perception). Our examples constitute only a modest selection from a vast corpus of British and American children's literature. In looking for the sources of nonsense and humour our attention will go both to language and to the visuality of the texts, the combination which undoubtedly makes them attractive for young receivers.

\subsection{What is nonsense?}

In semantics the terms sense, meaningfulness, and significance are only superficially synonymous, in fact ambiguous and theory-dependent notions. Yet for the sake of our ordinary parlance we can assume, quoting Edward Strachey's words from his Introduction to Edward Lear's Complete Nonsense (1846; 1871), that:

Sense is the recognition, adjustment and maintenance of the proper and fitting relations of the affairs of ordinary life. [...] we usually talk of sense as Common Sense. [...] Nonsense is the proper contrary of Sense.

(Lear 1994 [1846; 1871]: 7)

In spite of the fact that sense constitutes the "default value" and the ultimate goal of our interpretative efforts, every user of human language is capable of generating not only wellformed and meaningful structures but also all kinds of constructions that demonstrate aberration from norms. It is a paradox of sorts that the human beings, though being basically the homo sensicus, are endowed with a great capacity for acting and expressing themselves as the homo nonsensicus.

Nonsense as a descriptive category of human language has functioned in philosophical, logical, and linguistic literature under many names: anomaly, deviance, meaninglessness, nonsignificance, absurdity. Each of these terms is heavily theory-oriented and should be studied in its proper scholarly context. Of special interest is the term absurd, which in formal semantics appears mostly in the name of a reasoning pattern dubbed reduction ad absurdum, in reference to a contradictory set of premises that make the whole reasoning invalid. However, in literary criticism the absurd is widely recognized as the label for a specific genre, often used synonymously with the notion of nonsense and descriptive of any kind of textual incongruity (cf. Joanna Gavins' cognitive stylistic approach to the literary absurd, 2013). What is of particular interest for our considerations in this paper is the fact that nonsense has also been quite generally associated with such notions as the comical, the funny, the ludicrous. Yet, the phenomena of nonsense and humour should be taken as merely overlapping, that is nonsense by itself does not have to be humorous at all. Let us then very briefly consider the mechanisms inherent in natural language that allow us to create nonsensical texts/discourses. 


\subsection{Formal sources of nonsense-creation in language}

A few triggers of nonsense can be distinguished as operative universally in natural languages. Each one of them can potentially - but not necessarily - give rise to a comical effect (for a more detailed discussion of the sources of nonsense in natural language cf. ChrzanowskaKluczewska 2009; 2010).

\subsubsection{Logical deviance}

Logical deviance happens in language as a result of two closely related phenomena, namely reference-failure and problems with truth-valuation. The former is the use of non-denoting terms (more precisely, non-denoting in the real/actual world), typical of fictional creations but present also in our ordinary language in the form of hypothesizing, daydreaming, or invoking counterfactual situations. However, the sentence such as "The Pegasus has just landed near my house", in which the subject is a non-denoting term, is not completely meaningless or uninterpretable. The issue whether it qualifies as (a) straightforwardly false (Bertrand Russell's approach); (b) devoid of any truth-value, that is gappy in terms of valuation (Peter F. Strawson's suggestion, cf. Haack 1996: 51-52); or (c) possessing some intermediate truthvalue has engaged the attention of philosophers and logicians in a prolonged and still unsolved dispute between the supporters of classical bivalence and their opponents, that is the proponents of non-classical, many-valued systems of truth-valuation (cf. Haack 1996). This mediating value, often symbolized as I (intermediate, indeterminate) in some non-standard systems has been dubbed meaninglessness, non-significance, or nonsense (Routley 1969). Routley, as a proponent of a significance logic points to an apparent paradox: sentences classified as neither true nor false, that is non-significant or nonsensical in logical terminology, may be syntactically well-built and interpretable, thus 'significant' on the common interpretation of this adjective. We can surely say about our Pegasus sentence above that "it is significant (interpretable) even when it is not significant (neither true nor false)" (Routley 1969: 380). We can also claim that it has a potential to sound funny, thus to be an instance of linguistic humour. Generally speaking, on a strict logical approach, all fictional sentences due to reference failure and lack of truth-value - would qualify as 'non-significant' or 'nonsensical'. To remedy this situation, possible-worlds semantics can be invoked, under the tenets of which fictional sentences will find their valuation in a specific text-world (fictional world). This is a long-debated and exciting issue of the 'truth in fiction'/'truth in a model', which we have no space to discuss at this point.

\subsubsection{Semantic anomaly}

Semantic anomaly (semantic oddity) is a result of illicit combinations of parts of speech within phrases or sentences. In Chomskyan tradition it was called the violation of selectional restrictions, illustrated by the famous "Colorless green ideas sleep furiously". This kind of anomaly crops up abundantly in Victorian nonsense poetry, to quote only Lear's "brazen chops that wreathe/The tedious gloom of philosophic pills" (from the poem "Cold are the crabs"; Lear 1953: 63). The sentence demonstrates a triply wrong selection of adjectives to modify nouns ('brazen chops', 'tedious gloom', 'philosophic pills'), a wrong selection between the noun 'chops' (subject) and the verb 'wreathe' (predicator), as well as a wrong selection between the predicating verb 'wreathe' and the noun 'gloom' (the head of the nominal phrase functioning as the direct object). It looks like the more numerous instances of semantic oddity we encounter within a sentence, the more nonsensical and potentially funny it becomes. 


\subsubsection{Vagueness, indeterminacy}

Vagueness, indeterminacy - these are other features of natural language that produce obscure meaning and can hinder interpretation. In the traditional formal semantic approach, vagueness was associated mainly with imprecise predicates, mostly adjectives of a very general meaning, for which no clearly delimited denotational sets can be pointed out, such as 'long', 'short', 'big', 'small', 'old', 'baldish', etc. Apart from the semantic fuzziness and relativity of such predicates, the indeterminacy of certain referring expressions may also create the effect of vagueness, as with the noun phrase 'the academics', which can receive either a collective or a distributive interpretation. Vagueness possesses a strongly pragmatic aspect, namely the disambiguation of vague expressions can proceed only within a proper context.

\subsubsection{Syntactic ill-formedness}

Syntactic ill-formedness/structural ambiguity is related to experiments with the syntactic structure of utterances, explored widely in poetry as well as in experimental prose. The play with the syntactic structure can lead either to structural ambiguity (where more than one interpretation of a given expression is possible) or to a much more severe case of grammatical ill-formedness. Needless to say, both outcomes may result in a comical effect, notwithstanding their relative interpretability.

\subsubsection{Figuration}

Figuration, that is the use of stylistic devices that can occur on all levels of linguistic description (phonetic, morphological, syntactic, semantic, graphic), apart from its basic cognitive (epistemic) role, the rhetorical (persuasive) function and the aesthetic value (the embellishment of the text), may often participate actively in nonsense-generation. The case in point is catachresis. On the narrow reading, it can be taken to be a "bold" metaphor, sophisticated but often close to absurdity, either difficult to process or hardly interpretable at all, like Gertrude Stein's famous phrase "A silence a whole waste of a desert spoon" (Stein 1993 [1913]: 269). On the broad approach, catachresis can be taken as a generalized figure of logical abuse, encompassing such microfigures as oxymoron, paradox, reversal of chronology, etc. (cf. Chrzanowska-Kluczewska 2013). Connected with an excessive reliance on figurative devices of all types is the phenomenon of overcoding, that is a surplus of meaning generated in a given text, which often results in nonsense and is prone to trigger a comical effect. Already Aristotle warned less experienced orators against the misuse of metaphors in their speeches, lest they eclipse the meaning proper.

\subsubsection{Lack of cohesion and coherence}

Lack of cohesion and coherence - here we refer to two most important text-forming strategies (out of the list of seven standards of textuality as postulated by de Beaugrande and Dressler (1990). Whereas cohesion is an overt syntactic-semantic connectedness of discourse, coherence refers to a covert network of ideas that makes the text comprehensible and acceptable through providing a conceptual text-world that underlies the text as a linguistic realization. If either of them is lacking, the text loses its meaningfulness and becomes uninterpretable, a non-text, in fact. The tampering with cohesion and coherence has always belonged to the repertoire of experiments with language. 


\subsubsection{Decontextualisation}

Lack of proper pragmatic anchoring (decontextualization) - the absence of proper pragmatic grounding makes every text extremely difficult to process. Also, the failure of (re)contextualization, which is a sine qua non with our dealings with the texts that come from the past or from different social and cultural milieus, may lead to the rejection of a text as meaningless. The contemporary reader of Victorian nonsense literature will either appreciate its valour due to the knowledge of the context in which this literature was produced or else will try to recontextualize it through giving to it a new, "updated" interpretation.

\subsubsection{Phonetic experimentation}

Phonetic experimentation - experimentation with the phonetic resources of a given language has always been a rich field of literary activity, with poets in particular excelling in it. Punning, paronomasia, alliteration, the play with rhymes and the metre have been applied abundantly also in the poetry addressed to children, who all pass through the developmental phase of glossolaly, when meaningless combinations of sounds are produced. Children never lose flavour for it, as visible in the rhymes for young readers and not uncommon in folk songs. The play with the phonetic texture of language more often than not will create a humorous effect, as visible in the following limerick by Lear founded on a glossolalic, refrain-like utterance:

There was an old person of Wick,

Who said, 'Tick-a-tick, Tick-a-Tick;

Chickabee, Chickabaw,'

And he said nothing more,

That laconic old person of Wick.

(Lear 1994: 93, quoted also in Lecercle 1994: 107)

\subsubsection{Graphological experimentation}

Graphological experimentation - the play with the graphic shape of the text will possess a clearly gamesome dimension. The interplay of the two perceptual modalities - the verbal and the non-verbal, visual one - a prime instance of multimodality - can add to the absurdity/nonsensicality of the text. In poetry, where the rhymed stanzaic form is a norm, any departure from it will be functionally loaded.

Not too many studies on the nonsense-creation potential of the graphic layer of texts have engaged comprehensively with this issue in relation to children's literature. This article, due to its technical limitations, will point out to such an interplay, which can also produce a multimodal comical effect.

All the above-mentioned phenomena are related to a transgression of certain norms in language and especially in its written medium. All of them bear in themselves a nonsenseproducing and humour-triggering potential.

\section{Interplay of language with the visuality of the poetic text}

The ways in which a literary text qua a linguistic creation can be affected by its own graphic shape or by the separate visual additions that accompany it can be broadly subdivided into three classes:

1. Visual poetry (carmen figuratum, kinetic poetry) - in this tradition extending back to ancient Greece and Persia, the poem assumes a specific shape related to its main subject. In children's poetry the graphic form should be obvious for the ease of 
processing, while in adult texts it may constitute a puzzle. This is a case of Dylan Thomas's diamond-shaped devotional poems from the cycle Vision and Prayer composed in 1945 (cf. Thomas 2000). Several interpretations have been nonconclusively adduced to explain the selection of this particular graphic layout (among others, rhombus as a perfect shape, two pyramids joined at the bases, a person with the arms outstretched/a crucified person). To the contrary, in the famous $17^{\text {th }}$ century religious poems of George Herbert the shapes of an altar and of the bird's/angel's wings are easily recognizable. None of those poems is nonsensical or comical and the graphic shape enhances only the spiritual message of the verbal text, which in Thomas's case is difficult to access mainly due to its structural ambiguity.

2. Multimodal texts - on the so-called narrow interpretation of multimodality, they typically instantiate a co-occurrence of the verbal and the visual medium as functioning separately but supporting each other. Picture books for children and comic strips are exemplars of this type of multimodality. In the former the verbal part takes precedence over the visual (Victorian nonsense poetry for children belongs to this category), in the latter the visual part predominates and the textual inserts (bubbles) complement the graphic layer. Both these genres may but do not necessarily have to comprise any comical material.

3. Texts with phonetic play/instrumentation - though such texts do not boast a particular shape, the graphic arrangement of letters that represents various sound effects is of interest, proving that the phonetic, visual, and semantic layers in such texts (usually poems) are hardly separable, that is - borrowing an apt formulation from Jean-Jacques Lecercle - nonsense is polyphonic as a linguistic phenomenon.

\subsection{Examples of multimodality in British and American nonsense poetry for children}

Several examples of multimodal texts will be described below. Unfortunately, due to space limitations, we cannot show the reproductions of the illustrated material.

\subsubsection{Lewis Carroll, “A long tale”, Alice's Adventures in Wonderland}

It is a good example of pattern poetry, in which the poem's shape (Carroll 1981 [1865]: 19) relates deftly to one of the poetic personae (Mouse) and the story told by the narrator. The title is ambiguous on the phonetic level, playing on the homophonous pair 'tale' vs. 'tail'. The influence of the graphic (typographic) features on the interpretation of texts has been called grammatextuality (Lapacherie 1984, quoted in Roque 2008 [2005]). Typography is no longer transparent but becomes a meaning-carrier.

This kind of pattern poetry becomes a double challenge for the translator, who has to recreate both the verbal content and the visual form. The third challenge for the translator is preserving the humour of the original (if it happens to be funny as is the case discussed). Henri Bergson in his well-known essay Laughter ventures the following pessimistic opinion:

We must make a distinction, however, between the comic expressed and the comic created by language. The former could, if necessary, be translated from one language into another, though at the cost of losing the greatest portion of its significance when introduced into a fresh society different in manners, in literature, and above all the association of ideas. But it is generally impossible to translate the latter. It owes its entire being to the structure of the sentence or to the choice of the words [...] In this case, it is language itself that becomes comic.

(Bergson 2008 [1900]: 52-53)

Despite those qualms two Polish translations of "A long tale" are briefly mentioned below. 


\subsubsection{Maciej Stomczyński, "Ogonopowieść", Przygody Alicji w Krainie Czarów}

The translation of the homophonous English title ('tale' vs. 'tail') into Polish is creative, based on a neologism/blend 'ogonopowieść' ('the tale of a tail'; Carroll 1972: 34).

The humorous content and the visual shape have been preserved though the "tail" is thicker and has lost its elegance. The reason lies in a general morphological "heaviness" of the Polish language (length of words).

The protagonist called Fury is usually taken by the translators to be a cat, though the epithet 'cur' is misleading. Consequently, in Słomczyński's version 'Fury' is rendered as 'Kot Zły' ('Malicious Cat').

The melodic line of the poem is also well-preserved in translation.

\subsubsection{Elżbieta Tabakowska, "Dluga opowieść”, Alicja w Krainie Czarów}

Visually, the tail is the thickest (Carroll 2012: 27). The lexis is more contemporary, so the translation reflects the process of recontextualization, to make it more acceptable to the $21^{\text {st }}$ century readership.

'Fury' has been translated as 'Kot Bury' ('Gray Cat'). The title in Polish has lost the original homophony and refers only to the primary meaning of 'a long tale'.

Tove Jansson's picture above the poem, her own addition to the original text, showing the mouse, two other unidentified animals and the cat with a striped tail, is an exemplar of how the visual appended to a humorous text can heighten its impact owing to its own non-verbal comicality (cf. Chiaro 2017: 418-419 on an Italian translation that has totally changed the visuality of the poem).

\subsubsection{Lewis Carroll, the first stanza of the poem "Jabberwocky", Through the Looking Glass}

The stanza, in an archaized, elegant cursive script, should be read as a reflection in the mirror (a graphic trick: "a Looking-glass book"; Carroll 1981 [1871]: 117). "If I hold it up to a glass, the words will all go the right way again", explains Alice.

\subsubsection{Maciej Stomczyński, the translation of the same stanza, O tym, co Alicja odkryła po drugiej stronie Lustra}

The original cursive script in its archaic form has been faithfully preserved ("Lustrzana książka"; Carroll 1972: 21). The Polish translated stanza is - visually - a little bulkier than the original. The archaic graphic form of the text is important as it produces the aura of some legendary times in which romantic stories of brave knight fighting with monsters took place. The nonsensical content of the original at the verbal layer has been well preserved.

\subsubsection{Edward Lear, "An Old Man of Coblenz", A Book of Nonsense (1846) in Nonsense Books with authorial illustrations}




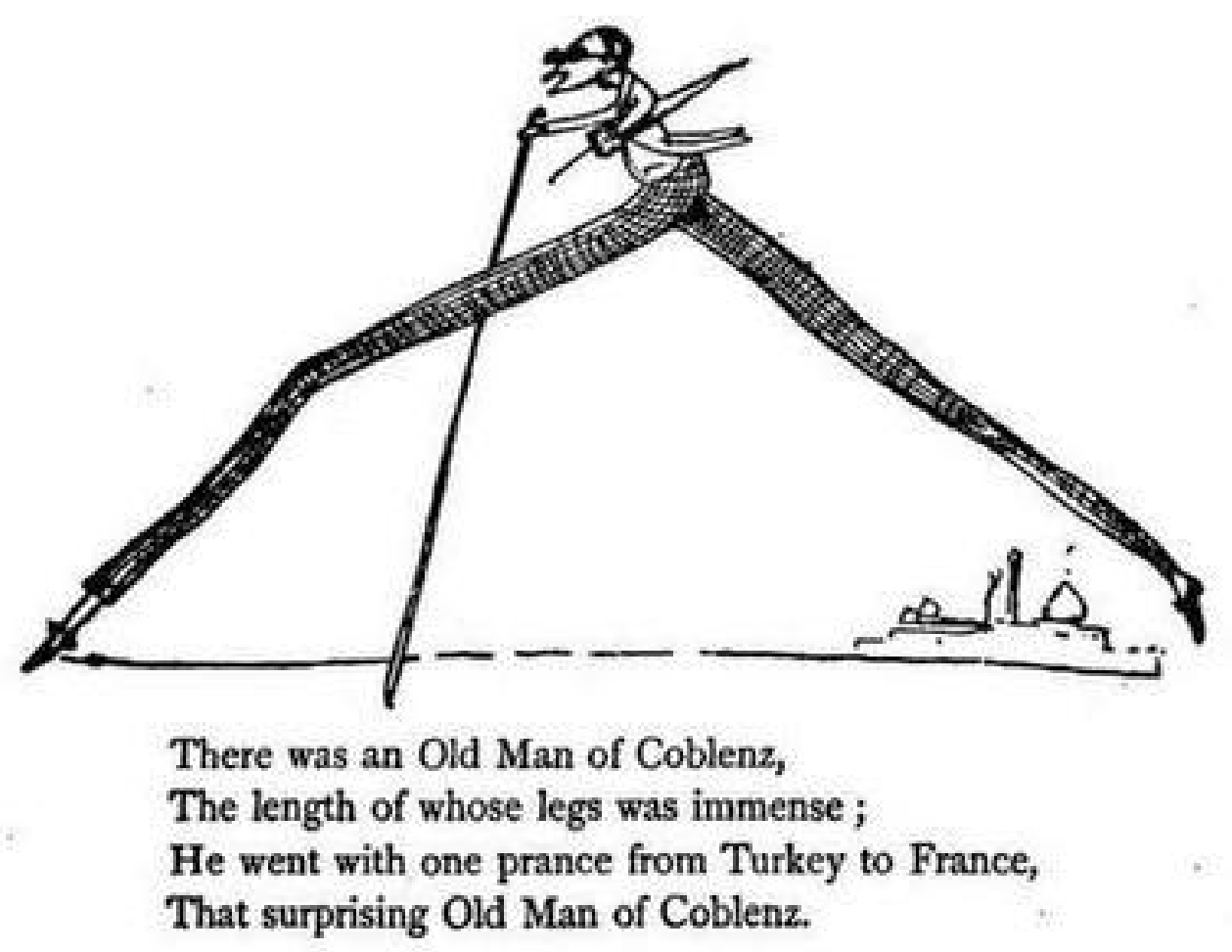

Figure 1. "An Old Man of Coblenz" by Edward Lear (1846). Public domain.

This limerick is a fine instance of multimodality, with the verbal part attached skilfully to the picture, which is nonsensical in itself, showing a man with unnaturally long legs striding across the Mediterranean Sea (cf. also Lear 2004). The text is as ludicrous as the picture, the latter based on what we could call a visual trope - a visual hyperbole, simultaneously an instance of visual humour. Exaggeration has functioned as an age-long tropical mechanism of nonsense and humour production (cf. Lecercle 1994: 106; Larkin-Galiñanes 2017: 12).

\subsubsection{Edward Lear, "There was an Old Man in a tree”, More Nonsense (1871-2) reprinted in The New Faber Book of Children's Poems, with an illustration by Sara Fanelli}

There was an old man in a tree,

Whose whiskers were lovely to see;

But the birds of the air, pluck'd them perfectly bare,

To make themselves nests in that tree.

$$
\text { (Lear } 1994 \text { [1871-2]: 117) }
$$

The limerick reappears in the $20^{\text {th }}$ century picture book for children (Sweeney 2001: 80), with a contemporary illustration replacing the original drawing by Lear himself. The drawing is funny in the way meant to be more acceptable to a contemporary young reader. The issue which cannot be overlooked at this point is whether we are licensed to introduce novel pictures into the text originally illustrated by the poet himself.

\subsubsection{Edward Lear, Nonsense Stories and Alphabets, authorial illustrations (1871)}

A was an Ape,

Who stole some white Tape,

And tied up his Toes 
In four beautiful Bows.

\title{
a
}

Funny old ape!

(Lear 1994 [1871]: 246)

This is another instance of multimodality - the graphic part, showing the monkey trying to embellish his toes, appears above the poem and so has been intertwined with the text proper. This educational poem is both nonsensical and laughable (as metatextually indicated in the text itself, which describes the monkey as 'funny'). The verbal absurdity is supported by an equally absurd picture.

\subsubsection{Edward Lear, Nonsense Stories and Alphabets (1871), authorial illustrations}

$$
\text { Y was a Yak }
$$

From the land of Tibet,

Except his white Tail

He was all black as Jet.

$$
\mathbf{y}
$$

Look at the yak!

(Lear 1994 [1871]: 258)

Like the previous example, it is an educational multimodal text. In fact, it is not heavily nonsensical (if nonsense can be measured on a scale) although yaks do not usually have white tails. Consequently, the unexpected juxtaposition of whiteness with the expected colour black makes the poem comical.

\subsubsection{Edward Lear, Nonsense Stories and Alphabets (1871), authorial illustrations}

\author{
$\mathbf{X}$ was once a great King Xerxes, \\ Xerxy \\ Perxy \\ Turxy \\ Xerxy \\ Linxy-urxy \\ Great King Xerxes!
}

(Lear 1994 [1871]: 244)

This poem-like piece is a skilful combination of typographic, phonetic (glossolalic) and morphological effects. It plays on neologisms; rhyming effects are obtained through the application of the common derivational suffix $-y$. This alphabetical entry is additionally supported with an absurd, funny drawing of Xerxes dancing, brandishing a sword and a lance.

\subsubsection{Edward Lear, "The history of the seven young storks", Nonsense Stories and Alphabets}

It is a short pedagogical narrative, funny but with a clear moral point about the tragic outcome of discord and fight. Seven young and stupid storks intend to feed on a frog:

[...] So being hungry, they immediately flew at the large Frog and were going to divide him into seven pieces, when they began to quarrel as to which of his legs should be taken off first. 
One said this and another said that, and while they were all quarrelling the Frog hopped away.

And when they saw that he was gone, they began to

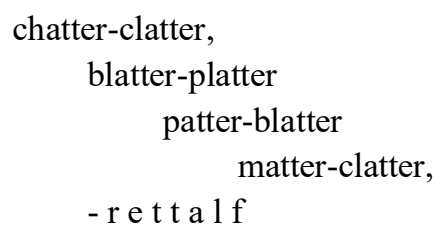

quatter more violently than ever. And after they had fought for a week they had pecked each other to little pieces, so that at last nothing was left of any of them except their bills. And that was the end of the Seven young Storks.

(Lear 1994: 222)

The story contains an insert which might be described as a piece of kinetic poetry, imitating the movement and the dynamic development of the plot (through iconicity). The graphic arrangement is accompanied by the play on onomatopoeias, which add to the instrumentation (cacophony which iconically represents the storks' fight).

Additionally, neologisms appear ('blatter', 'quatter'). The meaningless sequence of letters ' $r$ e $t \mathrm{t}$ a $1 \mathrm{f}$ ' marks the culmination of the quarrel. Incidentally, the letters can be rearranged, like in an anagram, to form the word 'flatter'.

Thus, the morphological, semantic, phonetic, and graphic layers of the story are deftly combined into an inseparable whole. This makes the text genuinely multimodal (the combined verbal, visual, and acoustic effects) and humorous due to the polyphony of several modes of expression.

\subsubsection{Mother Goose. Old Nursery Rhymes, compiled and illustrated by Arthur Rackam (1913)}

I quote only the initial and the closing part:

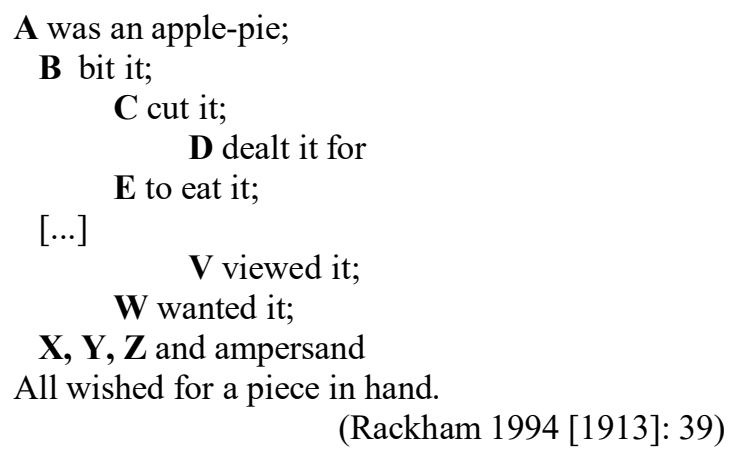

This educational abecedarius appears to be partly nonsensical, mainly due to the unexpected addition of the 'ampersand' to the company of the personified letters. It is also an instance of visual poem that zigzags down the page creating an effect of dynamic hilarity.

\subsubsection{Langston Hughes, "Sliver"}

Cheap little rhymes

A cheap little tune

Are sometimes as dangerous

As a sliver of the moon.

A cheap little tune 
To cheap little rhymes

Can cut a man's

Throat sometimes.

(Sweeney 2001: 70-71)

This highly ironical poem written by the famous Afro-American poet of the Harlem Revival makes an impression of being intended for a double audience, not necessarily only the youngsters, who might not be able to appreciate the poet's message. The poem is accompanied by a sketchy drawing of a personage (partly human, partly bird-like) with the head cut off by what looks like a sliver of the moon but has been composed of stylized letters and punctuation marks, evidently part of "cheap little rhymes" that despite their nice superficial appearance have led to this nonsensical decapitation.

\subsubsection{4. e.e. cummings, "hist wist"}

This is a triply multimodal composition playing on verbal, acoustic (onomatopoeias, glossolaly), and graphic effects, of which fragments only are quoted below:

$\begin{array}{ll}\begin{array}{l}\text { hist wist } \\ \text { little ghostthings } \\ \text { tip-toe } \\ \text { twinkle-toe }\end{array} & \begin{array}{l}\text { whisk look out for the old woman } \\ \text { with the wart on her nose } \\ \text { what she'll do to yer } \\ \text { nobody knows }\end{array} \\ \begin{array}{l}\text { little twitchy } \\ \text { witches and tingling } \\ \text { goblins } \\ \text { hob-a-nob hob-a-nob }\end{array} & \begin{array}{l}\text { for she knows the devil ooch } \\ \text { ach }\end{array} \\ \begin{array}{l}\text { [...] with scuttling } \\ \text { eyes rustle and run and } \\ \text { hidehidehide }\end{array} & \begin{array}{l}\text { green } \\ \text { dancing } \\ \text { dhisk }\end{array} \\ \end{array}$

(Sweeney 2001: 70-71)

In the poem by another famous American poet and great experimenter with the texture of language, the typography supports the phonetic effects and play on words. It is an amazing example of how morphological and lexical experiments intertwine with the instrumentation of the poem and its visual form, all of which jointly contribute to the overall humorous effect.

\subsubsection{John Agard, "Don't call alligator long-mouth till you cross river"}

Call alligator long-mouth

Call alligator saw-mouth

[...]

Call alligator scissors-mouth

Call alligator raggedy-mouth

[...]

Call alligator all dem rude word

But better wait

Till you cross river.

(Sweeney 2001: 148) 
Multimodality is a strong asset of this poem - the funny drawing of a scissor-like alligator with a wide-open mouth full of sharp teeth that appears below the poem, as if trying to swallow the poet's name mentioned there, helps to visualize the scene described in this singlestanza poem. It is ironical more than nonsensical. The verbal part is partly iconic as a consistent parallelism of verses at some point starts to resemble the alligator's gaping jaws. It also contains play on words (compounding), the use of a substandard slangy construction 'all dem rude word' (which is particularly funny) and symploce (repetition of the initial and final words in consecutive lines). It is humorous and educational at the same time, ending in a strong warning not to tease a dangerous creature, no matter how ludicrous it might look to us.

\title{
2.1.16. Ted Hughes, "Rat psalm"
}

$\mathrm{O}$ sing

The long-tailed grey worry of the night hours

Who always watches and waits

[...]

Even while you snore

O sing

Little Jesus in the wilderness

Carrying the sins of the house

Into every dish, $[\ldots]$

O sing

[...]

Garret-whacker, rick-lark

Sump-swab, cupboard adder $[\ldots]$

(Hughes 2008 [2005]: 143-145)

The poem contains an intertextual allusion to "A long tale" and to the biblical genre of elevated poetry called psalm yet is clearly blasphemous in its intention, comparing a rat to a "Little Jesus". The multimodality (the poem is accompanied by a portrait of a long-tailed rat in an upright position, holding a large spoon in its front paws) criss-crosses with phonetic effects and neological formations (creative compounds) visible in the last stanza, all adding to the attractiveness of the poem.

\subsubsection{Wojtek Graniczewski \& Ramon Shindler, "To Sigmund Freud”, Time for a Rhyme.}

The Limericks of T. J. Tonguetwister (2005), illustrated by A. Zaręba

\author{
There once was a doctor called Freud \\ Whose patients were often annoyed \\ But in rapid succession \\ He cured their depression \\ With techniques no one else had employed. \\ Sigmund Freud always wanted to find \\ What we hide in the depths of our mind \\ And absurd as it seems \\ By decoding our dreams \\ He revealed the true face of mankind.
}

(Graniczewski \& Shindler 2005: 48-49) 
This is a two-stanza limerick targeted at a double audience, as the adult readership will more readily recognize its ironical undertones. It has a traditional graphic shape, a very regular stanzaic rhymed form imposed by the genre it instantiates. It is multimodal, owing to an ornamental initial $\mathrm{T}$, like in old manuscripts, and a humorous picture of a doctor lying prostrate on the bed in his office as if he were a patient in need of a psychoanalytic treatment.

\title{
2.1.18. Ramon Shindler \& Wojtek Graniczewski, Found Alphabet (2005), illustrations by A. Andrzejewska \& A. Pilchowski-Radno
}

I find this the most proper tone on which to close the list of samples of nonsense which is simultaneously laughable and pleasurable. The book tells a story of the writers who while strolling on a "hot Sunday afternoon" discovered a magical house, full of rooms, hallways, "dark cellars and a large attic". There they found "treasures" - pieces of various materials, strange objects, all types of odds and ends. Out of these they made the letters of the alphabet, combining 'found objects' in an unusual creative way. The book is thus reminiscent of Lear's Alphabets, in that every letter is a creative image accompanied by a single-stanza rhymed poem to make it more memorable. It stands as an unusually creative way of recontextualizing the didactic poetry of Mother Goose and the pedagogical orientation of Victorian children's literature. A note from the Creators of the Found Alphabet, telling the story I summarised above, has been inscribed into a contour of a simple house with a chimney. The story says that the alphabet creators met a few wandering poets and showed them their letters, to which the poets composed the rhymes. It is worth quoting the closing fragment of this simple narration as it excellently summarizes the unbroken ties that connect the verbal and the visual:

\begin{abstract}
They [the poets] said, "Just as you take objects and put them together to make pictures, we take words and put them together to make poems." We said, "You create pictures with your poems." They said, "You make poems with your pictures." And then we realized that we all live in the house of our imagination.
\end{abstract}

(Shindler \& Graniczewski 2005: 31)

\section{2. "Reading images" in nonsense literature for children}

The title of this section, not without reason, is a travesty of a seminal work by Gunther Kress and Theo van Leeuwen (2006 [1996]) in the field of social semiotics, and particularly in the area of visual design, for which the authors have proposed a grammar. Among the constituents of this grammar, an important place is allotted to the phenomenon of modality. On analogy to linguistic modality, its visual counterpart defines the truth value, or the degree of probability of what the authors call visual propositions (Kress \& van Leeuwen 2006: 155).

In pictorial works (drawings, engravings, paintings, etc.), visual modality will roughly correspond to the dimension of realism/naturalism and the departures from it. Kress and van Leeuwen perceive visual modality as realized through a set of modality markers, all of which are gradable phenomena. The default value is for them a standard set by the contemporary (digital) photography:

1. colour saturation (ranging from the full colouring to the absence thereof, that is a realization in black and white);

2. colour differentiation (ranging from a rich gamut of colours to a monochrome rendering);

3. colour modulation (ranging from the colouring with many shades to plain/flat colours); 
4. contextualization (ranging from a detailed background to the background with few props and, ultimately, to a blank background);

5. representation (ranging from a maximal representation of pictorial detail to maximal abstraction); texture is included here as one of important factors (ranging from a rich texture to pure contours, like in a child's drawings);

6. depth (ranging from a full, central perspective to a flat representation, also typical of children's drawings);

7. illumination (ranging from a full interplay of light and shade to its absence, that is dullness);

8. brightness (ranging from several to only two degrees, i.e. black and white, or else two shades of gray; a diminished brightness leads to misty/hazy effects).

While examining the illustrated books for children from our list, which are all composite texts (in Kress and van Leeuwen's parlance) that combine the verbal with the pictorial material, it may come as a surprise that the visuals contained in them are marked by very low modality, judging by contemporary photographic standards. This, in particular, means that except for the Polish edition of Alice's Adventures in Wonderland (translated by Tabakowska and illustrated by Jansson), which boasts ten colour plates, the illustrations contained in the remaining books display the following values:

1. colour saturation - absent, i.e. black and white;

2. colour differentiation - very low, monochrome;

3. colour modulation - with some shades, or absent - flat black and white;

4. contextualization - the background richer in John Tenniel's drawings to Carroll's texts, otherwise very schematic or altogether blank;

5. representation - the classic illustrations by Tenniel closer to the engraving-like effect (Fig. 2), the number of details diminished in Lear's drawings.

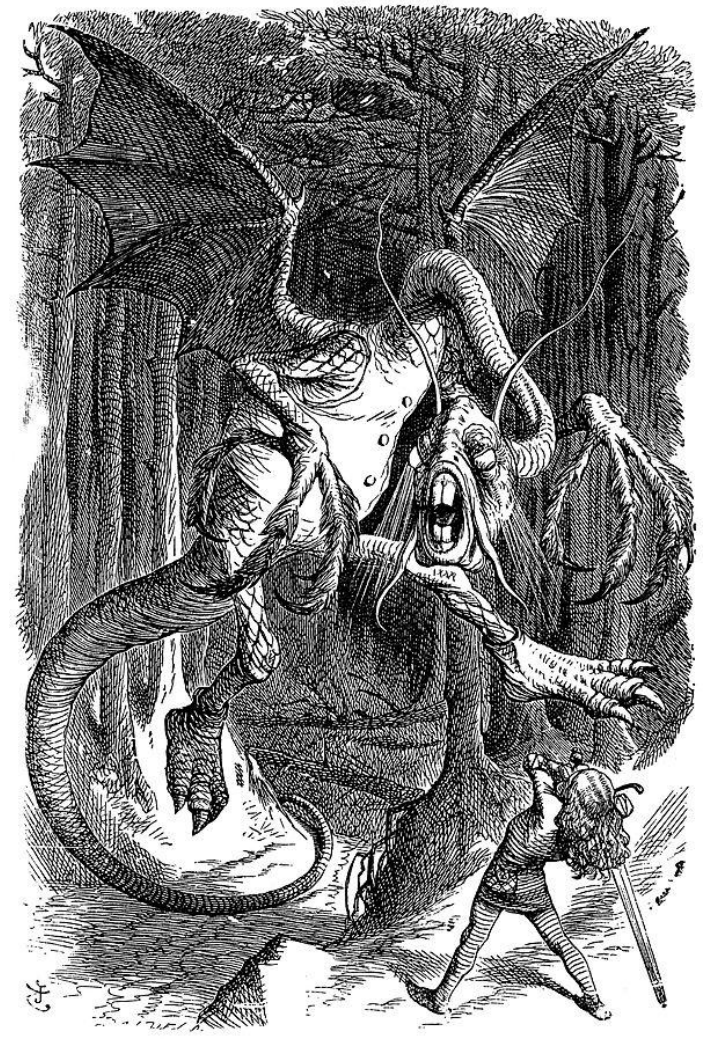

Figure 2. Jabberwocky by John Tenniel (1871). Public domain. 
The representation and texture are also very limited in the contemporary illustrations to The New Faber Book of Children's Poems executed by Sara Fanelli (2001) and to Ted Hughes' Collected Poems for Children by Raymond Briggs (2005). Brigg's illustrations are more modulated and with a richer texture, resembling rather the drawings by A. Dudziński that accompany Czesław Miłosz's (2001) translations of haiku poetry into English, whereas Fanelli's low-texture pictures, with their focus on contour bring to mind genuine works by children. Jansson's excellent illustrations (2012) possess a moderate modulation and texture and are closer in spirit to Brigg's drawings;

6. depth - a central perspective in Tenniel's drawings and Jansson's colour plates, otherwise flat representations dominate;

7. illumination - the highest illumination on colour plates by Jansson, diminished in Tenniel and Briggs, otherwise absent;

8. brightness - the highest (though not complete) brightness in Jansson's colour plates, otherwise diminished or lacking.

The only exception among the illustrated books for children analysed here is Found Alphabet (2005), which is a full-colour edition. Still, despite the colour saturation, differentiation, and modulation, the illustrations in the book display low modality as far as contextualization and representation are concerned. As if in compensation, the textual inserts that accompany those illustrations (one-stanza poems) are iconic in their shape, mirroring the visual side of the objects or creatures they describe.

The fact that the children's books scrutinized in this article have opted almost unanimously for black and white or monochrome illustrations, with a basically low modality may appear striking. The reasons are several, the obvious one being a powerful traditional British format set by Tenniel and Lear that has withstood the pressure of the changing fashions and given much joy to generations of readers - children and their adult caretakers alike. What is of special interest is how this illustrated material, seemingly terse in its visual modality, has proved successful as the visual constituent of both nonsense and humour.

Contrary to several studies on multimodal markers of humour in the acoustic sphere, for instance prosody (cf. Gironzetti 2017), the literature on the visual markers of humour is scarce. It would be extremely difficult to tabulate the visual markers of humour in the way Gironzetti has done for the phonetic aspects of jokes, if only for the non-discreteness of the visual representation. Future research on the visual sources of both nonsense and humour, which has to be conducted as an interdisciplinary project, will hopefully provide us with such data. At this point it can only be concluded that the triggers of humorous reactions in the young readers-viewers of multimodal texts need not be related to the presence of colour. Children of all epochs seem to have been endowed with such a kind of imagination that can draw pleasure from communing with a composite nonsensical text even if its visual side displays low modality. Apparently, the lack of colour and abstraction are no hindrances for the young readership to relish nonsense book illustrations.

\section{Conclusions - Henri Bergson revisited}

In order to provide a summary of various theoretical strains raised in this article, I would like to refer to a well-known and influential short treatise on laughter and its source, the comical, by Henri Bergson (2008 [1900]). Although over a century old, Bergson's theory of humour appears to me attractive for a number of reasons. 
First of all, it puts emphasis on the overlap of the absurd and the humorous. Despite the fact that nonsense and humour are distinct notional categories, our brief overview of children's poetry has shown that both these phenomena tend to co-occur. That is, it is as if children's nonsense poetry takes the effect of hilariousness for granted. Indeed, Bergson (2008 [1900]: 56) even ventured the following general assumption: "A comic meaning is invariably obtained when an absurd idea is fitted into a well-established phrase form". Bergson refers here to the purely linguistic humour, but our analysis demonstrates that verbal and visual humour in children's nonsense literature work in tandem. Whereas it is much easier to describe all the linguistic mechanisms of nonsense (Lecercle's study on Victorian nonsense is an excellent case in point), we still need to deepen the research on pictorial aspects of the ludicrous and on its ties with verbal humour. In brief, the multimodality of nonsense, especially in its graphic aspect, seems to be an inviting area for future studies.

Secondly, Bergson's ideas about the comical, both in language and social behaviour, bring together and anticipate what in modern humour studies has been categorized as three distinct models, i.e. the superiority theory, the incongruity theory and the release theory. Although Bergson talks mainly about adult participants in absurd-humorous situations and language use, the three theories developed in our times can find application to the study and explanation of nonsense and humour directed at young audiences/readership. LarkinGaliñanes (2017: 5) rightly points out that the aforementioned models of humour-creation and interpretation overlap. Due to space limitations we cannot consider here in any detail the issue whether children enjoy verbal and pictorial incongruity most, without getting involved in such patterns of behaviour as derision and disparagement of others (superiority theory), or whether they also need what Koestler (1964) called a "safety valve" effect of creative humour (release theory). This is a proper field of investigation for developmental psychologists and psycholinguists rather than linguists proper.

Thirdly, what I find of special import in Bergson's theorizing is the chain of interrelations between the following phenomena: logical and verbal absurdity $>$ humour and comic illusion $>$ dream illusion $>$ play/game (upon ideas and words) $>$ pleasure/amusement, but also irony/pessimism. I find the dimension of play/game of prime importance in the creation of humorous nonsense/nonsensical humour in children's literature (cf. also Lecercle 1994: 111). No matter whether we invoke Koestlerian bisociation, a script-switch of Victor Raskin (1985; 2017), or a semantic leap (frame-shifting) of Seana Coulson (2001), they are all strictly related to the emergence of enjoyment in young receivers of children's literature, who want to play and to be pleased. Also, children need not so much a release from everyday stress (like the adults do) but rather try at all costs to avoid boredom and quench their curiosity. Even on logical grounds, the need for inconsistency should be recognized as an important dimension of human intellectual make-up. Nicholas Rescher and Robert Brandom, in their defence of contradictions and inconsistency logic, say as follows (alluding also to D. E. Berlyne's psychological study of 1960):

Consistency is an epistemic desideratum - but not one that is absolute and unqualified. Man's mind does not thrive on consistency alone: the blockage to order that results from conflicting images is a crucial goad to inquiry and a pivotal motive for enlarging our information. Intellectual disequilibrium is a powerful constructive force. A critical aspect of man's evolutionary success lies in the fact that the central nervous system of higher animals demands expectationcontravening inputs to avoid boredom.

(Rescher \& Brandom 1979: 43)

Nonsense literature, founded on contradiction and inconsistency, helps children to exercise their imagination and to construe fictional worlds remote from our experience (cf. Chrzanowska-Kluczewska 2004 for more details; also Oring 2003 on the creation of joke 
worlds). No wonder then that in this very context Bergson invokes the experience of dream. Carroll's nonsensical prose is largely an instance of oneiric discourse and dream-like qualities pervade children's literature in general. Travels to and back from imaginary nonsensical and funny worlds are offered to children not only owing to infinite resources of natural language but also through the mediation of pictorial representation. The verbal and the visual play a supporting role in children's nonsensical and humorous travels across the imaginarium and deserve to be studied as two inseparable components of children's nonsense literature.

\section{References}

\section{Literary Sources}

Carroll, L. (1981 [1865; 1871]). Alice's Adventures in Wonderland \& Through the Looking Glass. With an Introduction by M. N. Cohen, ill. J. Tenniel. Toronto, New York, London, Sydney, Auckland: Bantam Books.

Carroll, L. (1972). Przygody Alicji w Krainie Czarów / O tym, co Alicja odkryła po drugiej stronie Lustra, transl. M. Słomczyński, ill. J. Tenniel according to the first English edition. Warszawa: Czytelnik.

Carroll, L. (2005 [2001]). The Complete Stories and Poems of Lewis Carroll. New Lanark, ML Scotland: Geddes \& Grosset.

Carroll, L. (2012). Alicja w Krainie Czarów, transl. and afterword E. Tabakowska, ill. T. Jansson. Kraków: Wydawnictwo Bona.

Graniczewski, W. \& Shindler, R. (2005). Time for a Rhyme. The Limerics of T.J. Tonguetwister, ill. A. Zaręba. Kraków: Astra/Bell.

Hughes, T. (2008 [2005]). Collected Poems for Children, ill. R. Briggs. London: Faber and Faber.

Lear, E. (1994 [1846; 1871; 1872]). Complete Nonsense, ill. by the author. Ware, Hertfordshire: Wordsworth Editions.

Lear, E. (1953). Teapots and Quails and Other New Nonsenses. Edited by A. Davidson \& P. Hofer. London: John Murray Publishers.

Lear, E. (2004 [1894]). Nonsense Books. With all the original illustrations. The Project Gutenberg e-Book. Retrieved October 31, 2017 from http://www.gutenberg.org/files/13650/13650-h/13650-h.htm\#rhymes.

Miłosz, Cz. (2001). Haiku, ill. A. Dudziński. Kraków: Księgarnia Haiku.

Rackham, A. (ed.) (1994). Mother Goose. Old Nursery Rhymes. Compiled and illustrated by A. Rackham. Ware, Hertfordshire: Wordsworth Editions.

Shindler, R. \& Graniczewski, W. (2005). Found Alphabet, ill. A. Andrzejewska \& A. Pilchowski-Ragno. Boston: Houghton Mifflin Company.

Stein, G. (1993). A Stein Reader. Edited and with an introduction by U. E. Dydo. Evanston, ILL: Northwestern University Press.

Sweeney, M. (ed.) (2001). The New Faber Book of Children's Poems, ill. S. Fanelli. London: Faber and Faber.

Thomas, D. (2000). Collected Poems 1934-53. London: Phoenix. 


\section{Critical literature}

Attardo, S. (ed.) (2017). The Routledge Handbook of Language and Humor. New York \& London: Routledge.

de Beaugrande, R.-A. \& Dressler, U. W. (1990). Introduction to Text Linguistics. London: Longman.

Bergson, H. (2008 [1900]). Laughter. An Essay on the Meaning of the Comic. Rockville, Maryland: Arc Manor.

Berlyne, D. E. (1960). Conflict, Arousal, and Curiosity. New York: McGraw-Hill.

Chiaro, D. (2017). 'Humor and translation', in Attardo, S. (ed.), The Routledge Handbook of Language and Humor, New York \& London: Routledge, pp. 414-429.

Chrzanowska-Kluczewska, E. (2004). Language-Games: Pro and Against. Kraków: Universitas.

Chrzanowska-Kluczewska, E. (2009). 'Introduction: What is (non)sense', in Chrzanowska-Kluczewska, E. \& Szpila, G. (eds.), In Search of (Non)Sense, Newcastle upon Tyne: Cambridge Scholars Publishing, pp. xi-xix.

Chrzanowska-Kluczewska, E. (2010). 'An unresolved issue: nonsense in natural language and non-classical logical and semantic systems', in Stalmaszczyk, P. (ed.), Philosophy of Language and Linguistics, Vol. 1, The Formal Turn, Frankfurt am Main: Ontos Verlag, pp. 43-62.

Chrzanowska-Kluczewska, E. (2013). Much More than Metaphor. Master Tropes of Artistic

Language and Imagination. Frankfurt am Main: Peter Lang Edition.

Coulson, S. (2001). Semantic Leaps. Frame-shifting and Conceptual Blending in Meaning Construction. Cambridge \& New York: Cambridge University Press.

Gavins, J. (2013). Reading the Absurd. Edinburgh: Edinburgh University Press.

Gironzetti, E. (2017). 'Prosodic and multimodal markers of humor', in Attardo, S. (ed.), The Routledge Handbook of Language and Humor. New York \& London: Routledge, pp. 400-413.

Haack, S. (1974/1996). Deviant Logic, Fuzzy Logic. Beyond the Formalism. Chicago \& London: The University of Chicago Press.

Koestler, A. (1964/1989). The Act of Creation. Harmondsworth: Penguin.

Kress, G. \& van Leeuwen, T. (1996/2006). Reading Images. The Grammar of Visual Design. Second edition. London \& New York: Routledge.

Larkin-Galiñanes, C. (2017). 'An overview of Humor Theory', in Attardo, S. (ed.), The Routledge Handbook of Language and Humor. New York \& London: Routledge pp. 4-16.

Lecercle, J-J. (1994). Philosophy of Nonsense. The Intuitions of Victorian Nonsense Literature. Abingdon, Oxon \& New York: Routledge.

Oring, E. (2003). Engaging Humor. Urbana, IL: University of Urbana Press.

Raskin, V. (1985). Semantic Mechanisms of Humor. Dordrecht: D. Reidel.

Raskin, V. (2017). 'Script-based semantics and ontological semantic theories of humor', in Attardo, S. (ed.), The Routledge Handbook of Language and Humor. New York \& London: Routledge, pp. 109-125.

Rescher, N. \& Brandom, R. (1979). The Logic of Inconsistency. A Study on Non-Standard Possible World Semantics and Ontology. Totowa, N. J.: Rowman \& Littlefield.

Roque, G. (2008 [2005]). 'Graphic presentation as expressive device', in Herman, D., Jahn, M. and Ryan, M-L. (eds.), Routledge Encyclopedia of Narrative Theory, London \& New York: Routledge, pp. 209-210.

Routley, R. (1969). 'The need for nonsense'. Australasian Journal of Philosophy 47(3), pp. 367-384. 